\title{
A PARTICIPAÇÃO DO TÉCNICO-ADMINISTRATIVO EM EDUCAÇÃO NA FORMAÇÃO INTEGRADA: UM ESTUDO DE CASO
}

\author{
Eniete de Oliveira Campos Furtado*; Alex Fernandes da Veiga Machado \\ *E-mail: eniete.furtado@ifsudestemg.edu.br \\ Instituto Federal de Educação, Ciência e Tecnologia do Sudeste de Minas Gerais \\ DOI: 10.15628/rbept.2020.10531
}

Artigo submetido em jun/2020 e aceito em nov/2020

\begin{abstract}
RESUMO
O ensino médio integrado se constitui num objetivo prioritário para a educação profissional técnica de nível médio dos Institutos Federais. A formação integrada visa à formação cidadã, uma formação ampla, omnilateral e não somente escolar. Nessa perspectiva, todos na escola são educadores, uma vez que transmitem valores e saberes em suas relações. Assim, este estudo pretende, por meio da pesquisa qualitativa, via estudo de caso, conhecer as percepções dos servidores técnico-administrativos em educação do campus Rio Pomba sobre sua participação na formação integrada dos alunos. Utilizou-se a entrevista semiestruturada para coleta dos dados que foram examinados por meio da análise de conteúdo com ajuda do software Iramuteq. Concluiu-se que os técnico-administrativos, apesar de não perceberem sua participação na formação integrada, têm essa participação de modo espontâneo e inerente.
\end{abstract}

Palavras-chave: Técnico-administrativo em educação. Formação integrada. Instituto Federal.

\section{THE PARTICIPATION OF THE TECHNICAL-ADMINISTRATIVE IN EDUCATION IN INTEGRATED FORMATION: A CASE STUDY}

\begin{abstract}
Integrated high school education is a priority objective for technical vocational secondary education at Federal Institutes. Integrated formation aims at citizen formation, a broad, omnilateral formation and not only school. In this perspective, everyone at school is an educator, since they transmit values and knowledge in their relationships. Thus, this study intends, through qualitative research, via case study, to get to know the perceptions of technical-administrative servants in education of the Rio Pomba campus about their participation in the integrated formation of students. The semi-structured interview was used to collect the data that were examined through content analysis with the help of the Iramuteq software. It was concluded that the technical-administrative servants, despite not realizing their participation in integrated formation, have this participation in a spontaneous and inherent way.
\end{abstract}

Keywords: Technical-administrative in education. Integrated formation. Federal Institute. 


\section{INTRODUÇÃO}

Os Institutos Federais de Educação, Ciência e Tecnologia (IFs) apresentam uma proposta de educação como instrumento de transformação social. Tornam-se "espaço privilegiado para a democratização do conhecimento científico e tecnológico e valorização do conhecimento popular" (PACHECO; SILVA, 2009, p.10).

Dentro dessa perspectiva, nos objetivos dos IFs, de que trata o inciso I do artigo 7º, da Lei 11.892/08, temos a educação profissional técnica de nível médio, na forma de cursos integrados, como prioritária (BRASIL, 2008).

Essa concepção de ensino médio visa o conhecimento, o trabalho e a cultura. Visa a "formação de sujeitos autônomos, tecnicamente capazes de responder às demandas da base científica digital-molecular da produção, mas politicamente, protagonista de cidadania ativa na construção de novas relações sociais" (RAMOS, 2014, p. 70).

Uma formação dessa natureza, integrada, cidadã, omnilateral necessita, de acordo com Pacheco (2011, p. 27), "romper com um formato consagrado, por séculos, de lidar com o conhecimento de forma fragmentada".

Instituições que primam pela formação integrada buscam "os índices de sucesso escolar ou acadêmico, a valorização de seus educadores da Rede, o conceito de educação que não se limita à ação escolar, mas envolve a comunidade" (PACHECO, 2011, p. 10).

Assim, os "funcionários têm uma função muito importante, pois seus afazeres diários contemplam uma dinâmica social ativa no processo de educar" (SILVA; NALDAL, 2016, p. 1).

Uma concepção de educação cidadã considera todos os integrantes da escola como protagonistas do processo educativo. Tal entendimento auxilia a vislumbrar "o traço pedagógico inerente às funções do trabalhador nãodocente" com definição mais clara de sua atuação educativa e sua importância (BRASIL, 2004, p. 15).

Nesse sentido, a educação escolar não se limita ao espaço da sala de aula e acontece através "das relações interpessoais entre todos os atores que atuam no ambiente organizacional de cada escola" (ANGST, 2017, p.1).

Assim, este estudo tem como objetivo conhecer as percepções dos técnico-administrativos em educação (TAEs) do campus Rio Pomba sobre o ensino médio integrado e os objetivos dos IFs. Objetiva também, conhecer sua participação na formação integrada e traçar um perfil desses servidores. Outra proposta é refletir sobre o papel educativo dos TAEs. 
Para tal desenvolveu-se uma pesquisa qualitativa, via estudo de caso, utilizando-se a entrevista semiestruturada com os TAEs que ingressaram no campus Rio Pomba nos últimos três anos, de agosto de 2016 a agosto de 2019, data de encerramento das entrevistas.

\section{O PAPEL EDUCATIVO DO TAE}

A divisão e a especialização do trabalho confinaram o ato educativo e pedagógico às salas de aula, segundo Monlevade (2014). No entanto, de acordo com Dourado (2012), a escola como espaço de socialização do aluno tem seu cotidiano marcado por várias práticas de formação dos sujeitos.

Uma nova concepção de escola e educação está se consolidando, uma educação mais abrangente, uma formação cidadã e para o mudo do trabalho que exige uma ressignificação dos espaços escolares (BRASIL, 2004).

Essa concepção de educação está presente na LDB, 2006, art.1울

A educação abrange os processos formativos que se desenvolvem na vida familiar, na convivência humana, no trabalho, nas instituições de ensino e pesquisa, nos movimentos sociais e organizações da sociedade civil e nas manifestações culturais. (BRASIL, 1996).

E está presente também nas "Diretrizes Indutoras para Oferta de Cursos Técnicos Integrados ao Ensino Médio na Rede Federal de Educação Profissional, Científica e Tecnológica" contidas no Fórum de Dirigentes de Ensino/CONIF (2018), nas definições de educação profissional como sendo uma educação ampla, com valorização da cultura e do trabalho, que impõe a superação do enfoque tradicional para o mercado de trabalho e mobiliza valores necessários para a tomada de decisões no mudo do trabalho.

Consolida-se assim, gradualmente, uma concepção de educação cidadã, que se afasta de modelos pedagógicos padronizados e excludentes, em favor de um ambiente de aprendizagens colaborativas e interativas, que considerem todos os integrantes da escola protagonistas do processo educativo (BRASIL, 2004, p. 14, grifo do autor).

Corroborando com esse pensamento, Leão (2009) coloca que a educação se dá nos vários espaços em que são transmitidos saberes e valores importantes para formação cidadã e não somente em sala de aula. Todos os profissionais que atuam dentro da escola têm importância e participam na formação do aluno, independente da função que exercem. 
Para Silva e Nadal (2016), a participação e/ou a integração do funcionário no processo educativo do aluno, vão de ações como alertas para não jogar papel no chão até orientações que o ajudem na sua formação para que sejam aceitos de forma digna perante a sociedade.

Ainda segundo os mesmos autores para que o funcionário possa ter de fato a função de educar e clareza quanto o seu papel de profissional da educação e principalmente como educador, ele precisa ter comprometimento com o processo ensino-aprendizagem e com a ética.

Desse modo, o trabalho educativo "pode ser desenvolvido por todos os profissionais envolvidos com a educação desde que esta seja concebida, conforme defende Kuenzer (2007), com um conceito mais amplo que incorpore todas as formas educativas" (MAGALHÃES, 2016, p. 15).

Tal entendimento permite enxergar o perfil pedagógico inerente às funções dos trabalhadores não-docentes, dando uma nova dimensão para sua importância e sua atuação educativa em espaços sociais e profissionais mais definidos (BRASIL, 2004).

O Decreto 5.154/2004 traz a possibilidade da integração do ensino médio à educação profissional, possibilitando "uma formação profissional mais consistente aliada à formação cidadã a que todos têm direito" (MARTINS e CZERNISZ, 2007, p. 18).

A Lei 11.091/2005 (PCCTAE) é promulgada logo após o Decreto $5.154 / 2004$ e traz um avanço com relação ao reconhecimento do trabalho educativo dos técnico-administrativos que passam a ser denominados, a partir de então, como técnico-administrativos em educação e suas funções passam a ser vinculadas ao ensino, a pesquisa e a extensão.

No artigo $8^{\circ}$ do PCCTAE consta:

I - planejar, organizar, executar ou avaliar as atividades inerentes ao apoio técnico-administrativo ao ensino;

II - planejar, organizar, executar ou avaliar as atividades técnicoadministrativas inerentes à pesquisa e à extensão nas Instituições Federais de Ensino;

III - executar tarefas específicas, utilizando-se de recursos materiais, financeiros e outros de que a Instituição Federal de Ensino disponha, a fim de assegurar a eficiência, a eficácia e a efetividade das atividades de ensino, pesquisa e extensão das Instituições Federais de Ensino (BRASIL, 2005).

No entanto, Magalhães (2016) faz algumas observações. Para a autora os incisos I e II concebem o trabalho educativo do ténico-administrativo de forma periférica com relação ao ensino, a pesquisa e a extensão. Já no item II 
é permitido ao técnico ser protagonista da pesquisa e da extensão, mas através de atividades técnico-administrativas.

Porém, "todos os que interagem com os educandos são educadores". Professores, técnicos e funcionários, dentro de suas especificidades, são todos trabalhadores em educação e a escola precisa reconhecer suas atuações como educativas (PACHECO, 2010, p. 9).

Contudo, é preciso ter em mente que "em complemento e como justificativa à propositura de que todos educam está formação humana integral" Magalhães (2016, p.38) e que a escola que se propõe a oferecer essa formação deve reconhecer os profissionais que nela atuam como educadores que contribuem para a formação de alunos nas várias dimensões da vida (MGALHÃES, 2016).

Corroborando com este pensamento temos as reflexões de Pacheco e Silva sobre a Lei 11.892/08: "os institutos federais podem atuar em todos os níveis e modalidades da educação profissional, com estreito compromisso com o desenvolvimento integral do cidadão trabalhador [...]" Pacheco e Silva (2009, p.8) e que os institutos federais devem a ter como uma das diretrizes "a compreensão de que o conhecimento deve ser tratado em sua completude, nas diferentes dimensões da vida humana [...]" ( PACHECO e SILVA, 2009, p.9).

\section{METODOLOGIA}

A pesquisa foi desenvolvida no campus Rio Pomba do IF Sudeste MG. Para traçar o perfil dos TAEs foram usados dados da Reitoria e da Coordenação de Gestão de Pessoas do campus e consulta aos Boletins de Serviço do campus e da Reitoria, disponibilizados nos respectivos sítios, além de dados fornecidos pela Diretoria de Extensão e diretoria de Pós-Graduação e Pesquisa.

Para o estudo de casos os sujeitos da pesquisa foram os TAEs que ingressaram no campus nos últimos três anos, de agosto de 2016 a agosto de 2019, data de encerramento das entrevistas.

A delimitação temporal se mostrou necessária, uma vez que o TAEs se constitui num grupo heterogêneo e bastante diversificado em função de suas várias atividades e cargos. Com essa delimitação foi possível ter uma amostra de técnicos no exercício de vários cargos e níveis atuando nos departamentos de ensino ou administrativo.

Com essa amostra, num total de vinte e cinco TAEs, também foi possível englobar técnicos com tempos diferenciados de serviço no IF e no campus. As movimentações previstas na Lei 8.112/90, tais como remoção, redistribuição, e um novo concurso para outro cargo, traz a possibilidade dos técnicos que 
entraram em exercício nos últimos três anos, já terem estado no campus em outro momento ou em outras unidades do IF.

A coleta dos dados iniciou somente após a aprovação do parecer consubstanciado do Comitê de Ética e Pesquisa do IF Sudeste MG de no 3.296.215, CAAE: 10611819.5.0000.5588.

As vinte e cinco entrevistas foram transcritas e preparadas para análise. Foram separadas as partes sobre o EMI e sobre a participação dos TAEs na formação dos alunos constituindo-se assim, em corpus para análise. Esse procedimento foi adotado para facilitar o entendimento das percepções dos TAEs do campus Rio Pomba. Cada corpus de texto é constituído pelas falas do TAEs que foram tratados como "tec", abreviatura de técnicos.

O Corpus geral sobre o EMI foi constituído por 25 (entrevistas) textos separados em 67 segmentos de textos (ST) com aproveitamento de 59 ST $(88,06 \%)$. Emergiram 2.183 ocorrências (palavras, formas ou vocábulos), sendo 551 palavras distintas e 306 com uma única ocorrência.

A partir destes dados, o Iramuteq fez uma análise de classificação hierárquica descendente (CHD) que consistiu na correlação dos ST e seus vocabulários para formar um esquema de hierárquico de classes de vocabulários.

O conteúdo analisado foi categorizado em seis classes: classe um com 10 ST (16,95\%), classe 2 com 11 ST (18,64\%), classe 3 com 9 ST (15,25\%), classe 4 com 9 ST $(15,25)$, classe 5 com 10 ST (16,95\%) e classe 6 com 10 ST (16,95\%). O que tornou possível ao pesquisador, inferir o conteúdo do corpus, nomear as classes e compreender grupos de discursos/ideias.

O Corpus geral sobre a participação dos TAEs na formação do aluno foi constituído por 25 (entrevistas) textos. Ao transportar para o software Iramuteq emergiram 2.597 ocorrências (palavras, formas ou vocábulos), sendo 490 palavras distintas e 241 com uma única ocorrência.

A participação dos TAEs na formação do aluno foi feita por meio da análise de similitude que é apresentada para auxiliar na identificação da estrutura de um corpus de texto. Baseada na teoria dos grafos possibilita a identificação das ocorrências entre as palavras e sua conexidade, auxiliando na distinção de partes comuns e específicas, a partir de variáveis ilustrativas de um corpus de texto (CAMARGO e JUSTO, 2013). As análises serão apresentadas na parte resultados e discussões, após a pesquisa documental que traça o perfil dos TAEs do campus Rio Pomba. 


\section{O PERFIL DO TAE DO CAMPUS RIO POMBA}

O PCCTAE estrutura os cargos dos TAEs em cinco níveis de classificação: A, B, C, D, E. Conceitua, no seu artigo 5oㅡ, inciso II, nível de classificação como sendo "conjunto de cargos de mesma hierarquia, classificados a partir do requisito de escolaridade, nível de responsabilidade, conhecimentos, habilidades específicas, formação especializada, experiência, risco e esforço físico para o desempenho de suas atribuições" (BRASIL, 1995).

O campus Rio Pomba de acordo com dados do sítio do campus, atualizados em 20 de agosto de 2019, consta com 159 TAEs em seu quadro de pessoal permanente. Desses quatro estão em exercício em outras unidades do IF ou cedidos para outras Instituições.

Assim, 155 TAEs estão em exercício no campus, 3 estão ocupando cargos de nível $A, 13$ de nível $B, 17$ de nível $C, 82$ de nível $D$ e 40 de nível E(IF Sudeste MG, 2019).

Quadro 1: Quadro de Escolaridade TAES/campus Rio Pomba

\begin{tabular}{|c|c|c|}
\hline $\begin{array}{ll}\text { Nível } & \text { de } \\
\text { capacitação } & \end{array}$ & $\begin{array}{l}\text { Escolaridade exigida para } \\
\text { ingresso no cargo }\end{array}$ & $\begin{array}{l}\text { Escolaridade TAE } \\
\text { Campus Rio Pomba }\end{array}$ \\
\hline $\mathbf{A}$ & Alfabetizado & $100,0 \%$ especialização \\
\hline B & Fundamental incompleto & $\begin{array}{l}15,3 \% \text { ensino médio } \\
7,7 \% \text { graduação } \\
77,0 \% \text { especialização }\end{array}$ \\
\hline C & $\begin{array}{l}\text { Fundamental completo e } \\
\text { médio completo }\end{array}$ & $\begin{array}{l}5,9 \% \text { ensino médio } \\
5,9 \% \text { graduação } \\
70,6 \% \text { especialização } \\
5,9 \% \text { mestrado } \\
11,7 \% \text { doutorado }\end{array}$ \\
\hline D & $\begin{array}{l}\text { Fundamental completo } \\
\text { mais curso de formação e } \\
\text { Médio profissionalizante ou } \\
\text { médio completo }\end{array}$ & $\begin{array}{l}\text { 3,6\% ensino médio } \\
\text { 7,4\% graduação } \\
68,3 \% \text { especialização } \\
20,7 \% \text { mestrado }\end{array}$ \\
\hline $\mathbf{E}$ & Graduação & $\begin{array}{c}2,5 \% \text { graduação } \\
60,0 \% \text { especialização } \\
32,5 \% \text { mestrado } \\
5,0 \% \text { doutorado } \\
\end{array}$ \\
\hline
\end{tabular}

Fonte: Dados pesquisa/Gestão de Pessoas campus Rio Pomba - IF SUDESTE-MG 20/08/19

Constata-se, pelo quadro acima, que o nível de escolaridade dos TAEs do campus Rio Pomba é muito superior ao exigido para o ingresso no cargo. Servidores técnico-administrativos altamente qualificados.

De acordo com a Lei 12.014/09 que altera o art. 61 da LD (Lei 9.364/96) todos os trabalhadores em educação são profissionais de educação básica, 
desde que sejam "portadores de diploma de curso técnico ou superior em área pedagógica ou afim" (BRASIL, 2009).

Uma vez constatada a profissionalização dos TAES do campus Rio Pomba através da escolaridade, qual a participação desses profissionais no ensino, pesquisa e extensão?

Pela legislação o reconhecimento dessa participação é progressivo, mas ainda tímido. Começamos pelo próprio PCCTAE, que como já dissemos, já trata esses profissionais como técnico-administrativos em educação. No seu artigo $8^{\circ}$ fica demonstrado o porquê dessa locução "em educação" evidenciado a importância desses técnicos "como sujeitos indispensáveis para o processo de ensino, pesquisa e extensão" (Lima, 2018, p. 352), tríade importantíssima presente nas finalidades dos Institutos Federais.

O PCCTAE, no seu artigo 3ํㅡㄹ também evidencia a importância dos TAEs para o alcance dos objetivos institucionais e a vinculação do trabalho desses profissionais para 0 alcance desses objetivos. Evidencia como o ensino, a pesquisa e a extensão estão indissociáveis das atividades laborais dos TAEs.

No entanto, a "invisibilidade" dos TAEs e a falta de reconhecimento, "por exemplo, de autorias de trabalhos de pesquisa, na formulação e implementação de projetos de extensão ou na gestão pedagógica do ensino" ainda é algo a ser superado. (AZEVEDO, ALMEIDA e SILVA, 2017, p. 71).

Apesar da dificuldade de se registrar e perceber a participação dessa categoria de profissionais nas distas "áreas fins" (grifo nosso) dos IFs, podemos evidenciá-la com mais facilidade quando falamos de cargos como, por exemplo, de técnico em laboratório.

Essa importância se torna evidente quando se têm em mente os projetos de ensino médio integrado onde teoria e prática devem ser vistos como dois elementos indissolúveis na ação formativa (Araújo e Frigotto, 2015). Do mesmo modo, fica evidenciado a importância do técnico em alimentos, técnico em agropecuária, técnico em enfermagem, e outros no processo ensino-aprendizagem.

Podemos continuar a reflexão e entender a importância do Pedagogo, Técnico em Assuntos Educacionais e outros quando analisamos as atribuições dos cargos. Mas e aqueles cargos em que as atribuições específicas não fazem de imediato uma ligação com as atividades educativas?

Primeiramente, precisamos considerar que os TAEs têm atribuições diferenciadas dos demais técnicos administrativos e que o PCCTAE vincula as atribuições desses técnicos ao desenvolvimento institucional, com objetivo de fortalecer o processo educacional. (LIMA, 2018).

Todos os cargos do PCTAE possuem atribuições em "diversas áreas que vão desde as atividades acadêmicas, administrativas, de laboratórios, até 
as áreas mais estratégicas, fortalecendo, portanto, as atividades de ensino, pesquisa e extensão" (LIMA, 2018, p.353).

Outro ponto a considerar são os valores e saberes aprendidos nas relações e no convívio com esses profissionais nas mais diferenciadas situações. "O ensino nasce na consciência política e desenvolvimento da percepção da cidadania, provocando no sujeito a discussão de sua realidade e convocando sua participação para a formação de uma sociedade integrada" (JESUS et al, 2018, p. 173).

Desse modo, os técnicos têm contato com estagiários, podendo supervisionar e orientá-los, participam das diversas comissões, conselhos consultivos e deliberativos e projetos, observando que muitos desses projetos ficam sem evidências por não serem registrados.

Buscando evidenciar essa participação dos TAEs no ensino, pesquisa e extensão, mesmo sabendo que muitos trabalhos, artigos, seminários, não são catalogados, obtivemos alguns dados de projetos de extensão com orientação de TAEs ou com TAEs na equipe.

Os projetos de extensão do campus Rio Pomba com envolvimento de alunos e com a participação dos TAEs tratam de artes e cultura, saúde física e emocional, alimentação, memória institucional, educação ambiental, ensino e outros (IF Sudeste MG, 2019).

De acordo com Diretoria de Pós-Graduação e Pesquisa em 2016 foi registrado um projeto de iniciação científica com orientação e outro com coorientação de TAE que teve duração de 2017 a julho de 2019. Observamos assim, que mesmo com grande carga de trabalho, os TAEs conseguem dedicar tempo a extensão e pesquisa.

Os trabalhos dos técnico-administrativos avançam com a participação na realização e organização de Simpósios de Ciência, Inovação e Tecnologia e de Ensino, Pesquisa e Extensão realizados no campus Rio Pomba. Participam também do Comitê de Ensino, do Comitê de Extensão, do Comitê Científico do Instituto de Pesquisa e Ciências Aplicadas (IPCA). Estão presentes nas comissões dos responsáveis pelos laboratórios do IPCA, dos responsáveis pela avaliação dos projetos de ensino, edital 4/2019, e comissão de reformulação do Regimento Interno do campus como consta nos boletins de serviços de 2016 a 2019 da Coordenação de Gestão de Pessoas. (IF Sudeste MG Pomba, 2018).

Para Silva e Nadal (2016) os afazeres diários dos funcionários, enquanto educadores, contemplam uma dinâmica social ativa importante que passa pela função de partícipes da gestão democrática participativa.

A participação dos TAEs nas instâncias colegiadas do campus Rio Pomba do IF Sudeste MG se faz presente através da participação no Conselho 
de campus, "órgão consultivo e deliberativo que tem a finalidade de colaborar para o aperfeiçoamento do processo educativo e zelar pela correta execução das políticas do IF no campus Rio Pomba" (IF Sudeste MG, 2018).

Com relação à estrutura organizacional, relativa aos cargos de direção e funções gratificadas que são remunerados, temos a seguinte participação dos TAEs no organograma do campus Rio Pomba. Ao agrupar a Direção Geral e as Diretorias sistêmicas, temos $16,6 \%$ ocupada por TAEs titulares e $83,3 \%$ de TAEs na substituição. Com relação às coordenações gerais os TAEs ocupam $62,5 \%$ como titular e $100 \%$ de substitutos. Ocupam $84,6 \%$ das FG 01 , funções gratificadas e $100 \%$ das substituições. 55,5\% das FG 02 e Fg 03 tanto como titulares e substitutos, conforme dados da Coordenação de Gestão de Pessoas em 22/08/2019.

Podemos concluir que os TAEs ocupam grande parte das funções da estrutura organizacional do campus Rio Pomba, nas quais estão incluídas funções administrativas e pedagógicas.

Segundo Monlevade (2012), os funcionários são educadores que se preocupam com a gestão material da educação na escola. "Não pode ser desprezada essa "materialidade" porque se trata dos canais por onde fluem as atividades de ensino-aprendizagem" (MONLEVADE, 2012, p.84).

\section{RESULTADOS E DISCUSSÕES}

Para Camargo e Justo, (2013) o trabalho não resume na apresentação dos dados fornecidos pelo software, o pesquisador precisa analisar os textos e interpretar os resultados.

Algumas colocações são importantes. Perguntou-se aos entrevistados se tiveram alguma capacitação ou informação sobre os Institutos Federais e seus objetivos. Todos disseram que não e que têm conhecimentos superficiais sobre os objetivos do Instituto e sobre a Rede Federal de Educação, Científica e Tecnológica.

A partir de perguntas norteadoras, a entrevista foi sendo desenvolvida com cuidado para explorar as informações relevantes trazidas pelos entrevistados de modo a conduzindo-los a reflexões e o despertar de percepções antes não existentes.

Em seguida foi perguntado para cada um dos entrevistados: o que você sabe sobre o EMI? A análise vem a seguir. 
Quadro 2: Categorias Conhecimento dos TAEs sobre EMI

\begin{tabular}{|c|c|c|c|c|c|}
\hline \multicolumn{6}{|c|}{ Ensino Médio Integrado } \\
\hline Classe 6 & Classe 1 & Classe 4 & Classe 3 & Classe 2 & Classe 5 \\
\hline \multirow[b]{2}{*}{$\begin{array}{c}\text { Formação } \\
\text { do } \\
\text { estudante } \\
\text { do EMI - } \\
16,9 \%\end{array}$} & \multicolumn{3}{|c|}{ Teoria e prática no EMI - 47,3\% } & \multicolumn{2}{|c|}{ Significado EMI- $35,5 \%$} \\
\hline & $\begin{array}{c}\text { Voltado } \\
\text { para uma } \\
\text { área } \\
\text { específica }\end{array}$ & $\begin{array}{c}\text { Complexidade } \\
\text { integraçãa } \\
\text { teoria/prática }\end{array}$ & $\begin{array}{l}\text { Ensino } \\
\text { voltado } \\
\text { para a } \\
\text { prática }\end{array}$ & $\begin{array}{l}\text { Curso técnico } \\
\text { profissionali- } \\
\text { zante }\end{array}$ & $\begin{array}{c}\text { Junção } \\
\text { ensino } \\
\text { médio com } \\
\text { o técnico }\end{array}$ \\
\hline \multicolumn{6}{|c|}{ Formas com ocorrência mais relevantes por ordem de qui-quadrado } \\
\hline $\begin{array}{l}\text { Estudante } \\
\text { Aula } \\
\text { Ali } \\
\text { Conseguir }\end{array}$ & $\begin{array}{c}\text { Específico } \\
\text { Exemplo } \\
\text { Área }\end{array}$ & $\begin{array}{l}\text { Estar } \\
\text { Ver } \\
\text { Aí } \\
\text { Muito }\end{array}$ & $\begin{array}{c}\text { Prático } \\
\text { Trabalhar } \\
\text { Não } \\
\text { Isolado }\end{array}$ & $\begin{array}{c}\text { Técnico } \\
\text { Profissionali- } \\
\text { zante } \\
\text { Técnico } \\
\text { Coisa } \\
\text { Estudar }\end{array}$ & $\begin{array}{l}\text { Junto } \\
\text { Curso }\end{array}$ \\
\hline
\end{tabular}

Fonte: elaborada pela autora; Iramuteq

A CHD apresenta as palavras mais expressivas da classe seis: estudante, aula, ali e conseguir. Essa categoria apresenta a formação proporcionada pelo EMI na visão dos TAEs e será denominada de Formação do estudante no EMI. A formação mais completa, no entanto, é percebida por um percentual menor dos TAEs, por isso a classe seis aparece mais isolada.

A dicotomia teoria/prática é presente no entendimento dos TAEs. Têmse a idéia de matérias teóricas que se complementam, passam a fazer sentido com a prática. Para um percentual significativo dos TAEs, o EMI traz uma formação em uma Área específica, denominação dada para a classe um. As palavras mais fortes desta classe são: específico, exemplo e área. Apresenta entendimento do EMI como a oportunidade de fazer um curso voltado para uma determinada área visando o ingresso no mercado de trabalho.

A classe um se subdivide em duas categorias: classe quatro, que passa a ser conhecida como Complexidade de integração teoria e prática, e a classe três, Ensino voltado para a prática objetivando o mercado de trabalho. As palavras mais expressivas da classe quatro, Dificuldade de integrar teoria e prática, são: estar, ver, aí e muito. A categoria Ensino voltado para a prática, traz as palavras: prático e trabalhar. Percepção de um curso prático objetivando o ingresso no mercado de trabalho.

O outro subgrupo traz as classes dois com as palavras: técnico e profissionalizante e a classe cinco com as palavras: junto e curso. As classes foram denominadas respectivamente como Curso técnico profissionalizante e Junção do ensino médio com o técnico. Essas duas categorias explicam o entendimento dos TAEs sobre a integração. Com relação à categoria/classe 
dois a percepção é que o EMl traz um algo mais, um curso técnico profissionalizante. O que explica a categoria/classe cinco, cujo entendimento do EMI é junção de dois cursos: ensino médio mais curso técnico.

O entendimento de integração é voltado para a junção do ensino médio com o técnico, com objetivo de formar profissionais para o mercado de trabalho. Obtenção de um curso profissionalizante e técnico, juntamente com o ensino médio, numa área específica.

A formação integrada no sentido de formar cidadãos críticos, autônomos e profissionais com fundamentação científica para se posicionarem no mundo do trabalho e na vida não é percebida pela maioria dos TAEs.

Assim, para Pacheco, $(2011$, p.16) derrubar as barreiras entre o ensino técnico e o científico, articulando trabalho, ciência e cultura na perspectivada emancipação humana, é um dos objetivos basilares dos Institutos Federais.

A falta de percepção de uma formação completa, integrada é percebida quando se pergunta aos TAEs sobre formação omnilateral, integrada. As respostas na maioria foram não conheço, não sei o que significa.

Para proporcionar uma reflexão, perguntou-se em seguida se uma formação cidadã não seria importante. Apesar de dizerem que sim, afirmaram que o foco principal é uma formação para o mercado.

Perguntou-se então sobre o trabalho, o que seria o trabalho, se existe diferença entre o trabalho de uma empresa para uma escola. Até o momento que foi perguntado: qual o produto do seu trabalho?

Cada um respondeu de acordo com o setor em que atua. Ou seja, o produto do trabalho estaria relacionando ao serviço desenvolvido de acordo com o cargo/profissão e com o setor. Então foi feita a pergunta: $O$ seu trabalho influencia na formação do aluno? Você participa da formação do aluno? A análise vem a seguir.

Quadro 3: Participação dos TAEs na formação integrada

\begin{tabular}{|l|l|}
\hline Participação indireta & Participação de apoio ao ensino \\
\hline Setores administrativos & Setores mais próximos ao ensino \\
\hline & \\
\hline
\end{tabular}

Fonte: Elaborada pela autora, Iramuteq

A partir da análise de similitude chegamos a duas categorias: Participação indireta principalmente nos setores administrativos e Participação 
de apoio ao ensino percebido pelos setores mais próximos ao ensino. A análise desses resultados aparece a seguir

A categoria Participação indireta é muito forte principalmente nos setores administrativos mais distantes do ensino. Mesmo aqueles que participam de cargos de direção ou funções de chefia, conselhos e supervisão de estágios não conseguem perceber a sua participação na formação do aluno, a não ser de forma indireta. Como uma "atividade-meio" para apoiar a formação escolar.

Não percebem a sua participação na formação não escolar. $\mathrm{Na}$ formação do cidadão, do homem em sua amplitude. As falas dos TAEs comprovam:

Diretamente não, indiretamente sim. Diretamente não por que acredito que a formação direta é quando você está muito atrelado ao contato né? Isso aí é minha opinião. Agora de forma indireta pelo processo administrativo como um todo, aí não tenho dúvidas que participo (Tec 12).

A categoria Apoio ao ensino está presente na fala dos TAEs que trabalham mais próximos ao ensino, na parte de análise e projetos, ajudando na aprendizagem. Percebem a participação na formação do aluno, mas somente como apoio ao ensino, ao professor.

\footnotetext{
Então tudo que a gente faz de acompanhamento de recuperação, de orientação do aluno, de pesquisas mesmo que a gente tem de levantamento de dados do aluno, que são acompanhados diariamente nos conselhos de classe e tudo mais, que a gente possa trazer essas informações para trabalhar junto com o professor (Tec14).

Então eu procuro contribuir dessa forma, trazendo essa visão do que o mercado exige, pede e tentando passar isso junto com os professores, com o departamento para uma formação melhor para o aluno (Tec 1).
}

A formação do aluno é vista somente com relação ao ensino formal, sistematizado, relacionado às disciplinas. A formação para o mercado e a formação escolar ofusca a percepção para outras formas educativas e formativas tão importantes quanto.

O capitalismo fragmenta o trabalho e isso também acontece na escola, divide o trabalho em atividade-meio e atividade-fim e o TAE não enxerga sua participação na formação do aluno, a não ser por essa visão fragmentada. 
Nesse sentido, a dicotomia atividade-fim e atividade-meio também se constitui num meio de mutilação e subalternização do trabalho dos TAEs. Corroborando com esse pensamento, Valle (2014) diz que a contribuição dos TAEs para atingir os objetivos da Universidade vem sendo, historicamente, considerada de forma secundária, como um meio para atingir determinados fins, quais sejam o ensino, a pesquisa e extensão. Assim também nos Institutos Federais.

Assim, a noção de formação omnilateral, integrada que o EMI busca e a participação dos TAEs na formação do aluno, relativa a outros saberes e conhecimentos, estão presentes, mesmo que forma inconsciente, mas inerente a esses educadores.

O que seria uma parte para a formação do aluno seria mais essa questão da memória institucional, do lugar que ele conviveu, que ele teve um ensino de qualidade, mais essa questão assim, mas ainda não desenvolvi nada para a formação do aluno, por que eu estou pouco tempo aqui (Tec 6).

Ou seja, o TAE não reconhece a memória institucional e o desenvolvimento de projetos nessa área como parte importante para a formação do aluno.

A gente já teve a oportunidade de viajar de ônibus com os alunos, levando os alunos, muitos gostam de viajar e ir perguntando, com muita educação, não só do trânsito, mas de outras formas também( Tec 11).

E aí quando você conversa com o estudante, você troca uma experiência, você conta talvez sua história, que é a minha. É bem assim, também tive que ralar um pouquinho também. Em tão eu acho que é um incentivo pro estudante. Aí ele fala poxa, legal eu também posso chegar lá. Acho que é uma forma de incentivar (Tec 13).

Você pega eles no momento de mais fragilidade, né. Tanto emocional, às vezes até físico, né. Então a gente, eles acabam se abrindo mais com a gente, conversando e aí depois eles passam lá e fala assim, olha melhorei a minha garganta, essa semana eu tive que tomar injeção. Eles me contam tudo, aí vão contando (Tec 10).

Observamos que os TAEs estão envolvidos em muitas ações que contribuem para a formação do aluno.

Como foi observado por Valle (2014), existe uma alienação por parte dos técncico-administrativos sobre seu trabalho educativo e os objetivos da instituição, pois eles estão de várias formas, por meio de atitudes e ações, 
ajudando o aluno na parte emocional, física, ética. Proporcionam o desenvolvimento não só escolar, mas atuam para uma formação omnilateral, integrada, completa, mesmo sem essa noção sistematizada, consciente.

\section{CONSIDERAÇÕES FINAIS}

Os Institutos Federais de Educação, Ciência e Tecnologia têm uma missão social de levar a várias regiões do país, não apenas tecnologias para 0 desenvolvimento regional e do país, mas uma educação em vários níveis para proporcionar uma formação completa, cidadã, tornando seus alunos cidadãos autônomos, agentes de sua história.

Uma Instituição que tem o EMI como um dos objetivos prioritários, que prima pela educação omnilateral e valoriza a relação entre trabalho, educação e cultura não pode considerar somente a educação formal

A educação se dá em vários espaços e não só nas salas de aulas através das disciplinas curriculares. A educação acontece através dos diversos saberes que são transmitidos nos diversos espaços por todos os profissionais de educação.

Todos que trabalham numa escola são educadores. Nesta perspectiva temos os técnico-administrativos em educação do campus Rio Pomba, profissionais em educação altamente qualificados, com educação formal bem acima da exigida pelos cargos que ocupam, mas que demonstraram não terem conhecimentos aprofundados sobre os Institutos Federais e seus objetivos, sobre o EMI e a formação omnilateral e tão pouco sobre seu papel na formação do aluno.

O EMI integrado não é compreendido pelos TAEs como um ensino que permite, a partir do trabalho, proporcionar uma formação com fundamentação científica e completa, para formar, não só profissionais, mas cidadãos capazes de se posicionarem no mundo do trabalho, ou seja, no mercado, na política, na sociedade, de forma autônoma.

Os TAEs do campus Rio Pomba não percebem sua participação na formação do aluno, a não ser de forma indireta e com relação ao apoio ao ensino, fruto da divisão social do trabalho da sociedade capitalista que fragmenta e empobrece o trabalho.

No entanto, foi possível verificar a sua atuação em várias atividades como projetos de pesquisa e extensão, acompanhamento e apoio ao ensino formal, atuação em várias comissões e conselhos, inclusive conselhos consultivos e deliberativos e na gestão administrativa e pedagógica do campus Rio Pomba. 
Constata-se também a sua atuação na transmissão de valores, ética e profissionalismo. Assim como a sua participação na formação do aluno através da memória institucional e participação em projetos culturais e na transmissão de saberes diversos. Não podemos deixar de perceber a participação desses técnicos/educadores na formação física, psicológica e emocional do aluno.

Concluímos que o EMI, formação omnilateral e os objetivos dos IFs não são conhecidos pelos TAEs em sua amplitude. Que a participação na formação omnilateral dos alunos não é percebida de forma sistematizada e consciente no trabalho desses TAEs, no entanto, é espontânea, inerente e existente em suas várias atuações.

O que nos leva a constatar que, se esses conhecimentos e conceitos fizessem parte de sua capacitação e fossem introduzidos a esses educadores, poderiam desenvolver suas atividades de modo mais coerente e consciente com contribuições ainda mais relevantes para a formação integrada e os objetivos dos Institutos Federais.

Desse modo, os TAEs seriam colaboradores/educadores conscientes em sua prática e não executores de tarefas sem conexão com as funções educacionais, históricas, socioeconômicas e políticas do local onde trabalham, contribuindo ainda mais para a participação consciente no processo ensinoaprendizagem, na formação do aluno e no fortalecimento dos IFs.

\section{REFERÊNCIAS}

ARAÚJO, R. M. L.; FRIGOTTO, G. Prática pedagógica e ensino integrado. Revista Educação em Questão. Natal, 2015, v. 52, n 38, p.61-80, mai/ago. Disponível em: $<$ https://periodicos.ufrn.br/educacaoemquestao/article/view/7956/5723>. Acesso em: 16 jul. 2019.

ANGST, Francisco. A Escola e seus Atores: os funcionários de escola. In: SIMPÓSIO IBEROAMERICANO EM COMÉRCIO INTERNACIONAL, DESENVOLVIMENTO E INTEGRAÇÃO REGIONAL, VIII. GT VII Desenvolvimento e Políticas Públicas; 2017, UFFS, campus Cerro Largo. Disponível em: <https://www.uffs.edu.br/campi/cerro-largo/viii-simposioiberoamericano-de-cooperacao-para-o-desenvolvimento-e-a-integracaoregional/anais>. Acesso em: 16 jul. 2019.

AZEVEDO, G. C.; ALMEIDA, M. C.; SILVA, P. V. Relato de Experiência - O Seminário de Integração dos Técnicos Administrativos em Educação da UFRJ (SINTAE UFRJ): dados sobre participação no evento e sobre formação do corpo técnico. Gestão Pública: A visão dos técnicos administrativos em educação das universidades públicas e institutos federais, vol. 4. Geovane 
Santana dos Santos ... [et al.]. (org.) - São Carlos, SP : Pedro \& João, 2017. 367 p.: il. (algumas color.). Disponível em:

https://taepublicaartigoselivros.files.wordpress.com/2018/03/4c2ba-volumegptae-2017.pdf. Acesso em: 12 set. 2019.

BARDIN, Laurence. Análise de conteúdo. Lisboa: Edições 70, 2002. Disponível em:

<https://edisciplinas.usp.br/pluginfile.php/4295794/mod_resource/content/1/BA RDIN\%2C\%20L.\%20\%281977\%29.\%20An\%C3\%A1lise\%20de\%20conte\%C3 \%BAdo.\%20Lisboa_\%20edi\%C3\%A7\%C3\%B5es\%2C\%2070\%2C\%20225..pdf >. Acesso em 20 jan. 2020.

BRASIL. LEI 8.112, de 11de dezembro de 1990. Dispõe sobre o regime jurídico dos servidores públicos civis da União, das autarquias e das fundações públicas federais. Diário Oficial da União. Brasília, 12 dez. 1990. Disponível em: <http://www.planalto.gov.br/ccivil_03/LEIS/L8112cons.htm>. Acesso em: 08 nov. 2018.

BRASIL. Lei 9.394, de 20 de dezembro de 1996. Estabelece as diretrizes e bases da educação nacional. Diário Oficial da União. Brasília, DF, 23 Dez. 1996. Disponível em: <http://www.planalto.gov.br/ccivil_03/leis//9394.htm>. Acesso em 30 nov. 2018.

BRASIL. Ministério da Educação e Cultura. Por uma política de valorização dos trabalhadores em educação: em cena os funcionários da escola. Brasília. MEC/SEB, 2004. Disponível em:

$<$ http://www.dominiopublico.gov.br/download/texto/me000489.pdf>. Acesso em: 12 abr. 219.

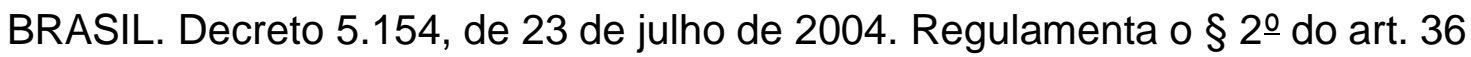
e os arts. 39 a 41 da Lei $n=9.394$, de 20 de dezembro de 1996, que estabelece as diretrizes e bases da educação nacional, e dá outras providências. Diário Oficial da União, Brasília, DF, 26 jul. 2004. Disponível em:

$<$ http://www.planalto.gov.br/ccivil_03/_Ato2004-

2006/2004/Decreto/D5154.htm>. Acesso em 22 nov. 2018.

BRASIL. Lei 11.091, de 12 de janeiro de 2005. Dispõe sobre a estruturação do Plano de Carreira dos Cargos Técnico-Administrativos em Educação, no Âmbito das Instituições Federais de Ensino vinculadas ao Ministério da Educação, e dá outras providências. Diário Oficial da União. Brasília, 13 jan. 2005. Disponível em: <http://www.planalto.gov.br/ccivil_03/_ato20042006/2005/lei/l11091.htm>. Acesso em 22 nov. 2018.

BRASIL. Lei 11.892, de 29 de dezembro de 2008. Institui a Rede Federal de Educação Profissional, Científica e Tecnológica, cria os Institutos Federais de Educação, Ciência e Tecnologia, e dá outras providências. Diário Oficial da União. Brasília, DF, 30 dez. 2008. Disponível em: 
<htpp://www.planalto.gov.br/ccivil_03/_Ato2007.../Lei/L11892.htm>. Acesso em 30 nov. 2018.

BRASIL. Lei 12.014 de 06 de agosto de 2009. Altera o art. 61 da Lei no 9.394 , de 20 de dezembro de 1966, com finalidade de discriminar as categorias de trabalhadores que se devem considerar profissionais da educação. Diário Oficial da União. 07 ago.2009. Disponível em: <http://www.planalto.gov.br/ccivil_03/_ato2007-2010/2009/lei/112014.htm>. Acesso em: 01dez. 2018.

CAMARGO, B. V.; JUSTO, A. M. IRAMUTEQ: Um Software Livre Gratuito para Análise de Dados Textuais. Temas em Psicologia. 2013, vol.21, n.2. p.513-518. Disponível em: < http://pepsic.bvsalud.org/pdf/tp/v21n2/v21n2a16.pdf>. Acesso em 24 mar. 2020.

DOURADO, Luiz Fernando. Gestão em Educação Escolar. 4. ed. Cuiabá, Brasil, Universidade Federal do Mato Grosso. Rede e-tec, Brasil, 2012. Ministério da Educação, Secretaria de Educação Profissional e Tecnológica. Disponível em:

$<$ http://portal.mec.gov.br/index.php?option=com_docman\&view=download\&alia $\mathrm{s}=33461$-02-disciplinas-form-pedagogica-caderno-06-gestao-em-educacaoescolar-pdf\&category_slug=fevereiro-2016-pdf\&ltemid=30192>. Acesso em 01 jun. 2019.

IF SUDESTE MG - Campus Rio Pomba. Gestão de Pessoas. Boletins 2019. Disponível em:

$<$ https://www.ifsudestemg.edu.br/documentosinstitucionais/unidades/riopomba/ gestao-de- pessoas/boletins-de-servico>. Acesso em: 18 ago. 2018

IF SUDESTE MG - Campus Rio Pomba. Gestão de Pessoas. Quadro de referência dos servidores técnico-administrativos. Disponível em:

$<$ https://www.ifsudestemg.edu.br/documentosinstitucionais/unidades/riopomba/ gestao-de- pessoas/boletins-de-servico>. Acesso em: 18 ago. 2018

Diretrizes Indutoras da Oferta de Cursos Técnicos Integrado ao Ensino Médio na Rede Federal de Educação Profissional, Científica e Tecnológica In: FORUM DE DIRIGENTES DO ENSINO/CONF set 2018. Disponível em: $<$ https://www.ifsc.edu.br/documents/38101/1079513/Diretrizes+EMl++Reditec2018.pdf/0cd97af4-bad5-b347-4869-7293ac87eb69>. Acesso em: 10 jun. 2019.

JESUS, Carlos Silva de et al. Reflexões sobre Técnica e Espaço na Educação não Formal. Synesis, v.10, n.2, p. 168 - 180, ago/dez 2018. Disponível em: < http://200.156.15.185/seer/index.php/synesis/article/view/1611 >. Acesso em: 03 mar. 2019.

LEÃO, Roberto Franklin. Organização e valorização dos funcionários. Cenário Atual e Desafios. Revista Retrato da Escola, Brasília, v.3, n.5, p.313-323, 
jul./dez. 2009. Disponível em: <file:///C:/Users/Usuario/Downloads/25-735-1PB.pdf>. Aceso em: 01 jun. 2019.

LIMA, Sílvia Elaine Almeida. O papel dos técnico-administrativos em educação nas atividades de ensino, pesquisa e extensão. Gestão Pública: A visão dos Técnico-Administrativos em Educação das Universidades Públicas e Institutos Federais. São Paulo. v. 5, 2018. p. 343-358. Disponível em: <https://taepublicaartigoselivros.files.wordpress.com/2018/12/GPTAE-volume52018.pdf\#\%5B\%7B\%22num\%22\%3A2317\%2C\%22gen\%22\%3A0\%7D\%2C\% 7B\%22name\%22\%3A\%22XYZ\%22\%7D\%2C82\%2C756\%2C0\%5D >. Acesso em 20 mar. 2018.

MAGALHÃES, Caroline Stéphanie Campos Arimatéia. Trabalho educativo do técnico-administrativo do IFRN/CNAT: consensos e dissensos. Natal, RN, 2016. Dissertação apresentada ao Programa de Pós-Graduação em Educação Profissional (PPGEP) do Instituto Federal de Educação, Ciência e Tecnologia do Rio Grande do Norte. Disponível em:

<https://memoria.ifrn.edu.br/bitstream/handle/1044/1389/Caroline\%20Stéphani e\%20-\%20TRABALHO\%20EDUCATIVO\%20DO\%20TÉCNICO-

ADMINISTRATIVO\%20DO\%2OIFRN-

CNAT_CONSENSOS\%20E\%20DISSENSOS.pdf?sequence=1\&isAllowed=y.Ac >. Acesso em: 02 abr. 2019.

MARTINS, S. A. J.; CZERNISZ, E. C. DA S. Ensino Médio/Educação Profissional: a serviço de quem? Plano de Desenvolvimento Educacional do Estado do Paraná. Desenvolvimento Educacional do Estado do Paraná. 2007, p. 33. Disponível em:

<http://www.gestaoescolar.diaadia.pr.gov.br/arquivos/File/producoes_pde/md_s uzeti_aparecida_juliani_martins.pdf. Acesso em 24 jun. 2019>. Acesso em: 02 abr. 2019.

MONLEVADE, João Antônio Cabral. Funcionários de Escolas: cidadãos, educadores, profissionais e gestores. Rede e-tec. 4. ed. Cuiabá, Universidade Federal do Mato Grosso, Rede e-tec, Brasil , 2012 Ministério da Educação, Secretaria de Educação Profissional e Tecnológica. Disponível em: $<$ http://portal.mec.gov.br/index.php?option=com_docman\&view=download\&alia $\mathrm{s}=33411$-02-disciplinas-form-pedagogica-caderno-01-funcionarios-de-escolacidadaos-educadores-profissionais-e-gestores-pdf\&category_slug=fevereiro2016-pdf\&ltemid=30192>. Acesso em: 01 jun. 2019.

MONLEVADE, João Antônio Cabral de. Identidade, carreira e jornada dos profissionais de educação. Cadernos de Educação, Brasília, n.26, p.79-97, jan.jul/2014. Disponível em: <https://www.sinprodf.org.br/wpcontent/uploads/2015/08/05-identidade-carreira-e-jornada-dos-profissionais-daeduca\%C3\%A7\%C3\%A3o.pdf>. Acesso em: 26 jun. 2019. 
PACHECO, Eliezer Moreira. Os Institutos Federais Uma Revolução da Educação, Profissional e Tecnológica. Ebook Brasília, 2010. Disponível no site: <http://proedu.rnp.br/bitstream/handle/123456789/1274/Os\%20institutos\%20fe derais\%20-\%20Ebook.pdf?sequence=1>. Acesso em 13 jun. 2018.

PACHECO, E. M; SILVA, C. J. R. (org.). Institutos Federais Lei 11.892, de 29/12/2008: comentários e reflexões. Natal, IFRGN, 2009. Disponível em: $<$ http://portal.mec.gov.br/index.php?option=com_docman\&view=download\&alia $\mathrm{s}=3753$-lei-11892-08-if-comentadafinal\&category_slug=marco-2010pdf\&ltemid=30192>. Acesso em: 8 jul. 2019.

PACHECO, Eliezer Moreira (org). Institutos Federais: Uma Revolução na Educação Profissional e Tecnológica. Institutos Federais Uma Revolução na Educação Profissional e Tecnológica. Brasília/São Paulo. Fundação Santillana Ed. Moderna. 2011. p.13-32. Disponível em: $<$ https://fundacaosantillana.org.br/wpcontent/uploads/2019/12/67_Institutosfede rais.pdf>. Acesso em: 13 mar. 2020.

RAMOS, Marise. História e Política da Educação Profissional. Coleção Formação Pedagógica. IFPR-EAD. 1르 edição. Curitiba. PR. 2014. Vol.5, p.1121. Disponível em: <https://curitiba.ifpr.edu.br/wpcontent/uploads/2016/05/Hist\%C3\%B3ria-e-pol\%C3\%ADtica educa\%C3\%A7\%C3\%A3o-profissional.pdf>. Acesso em: 13 mar. 2020.

SILVA, Caetana Juracy Rezende (org.). Institutos Federais Lei 11.892, de 29/12/2008: comentários e reflexões. Natal, IFRGN, 2009. Disponível em: $<$ http://portal.mec.gov.br/index.php?option=com_docman\&view=download\&alia $\mathrm{s}=3753$-lei-11892-08-if-comentadafinal\&category_slug=marco-2010pdf\&ltemid=30192 $>$. Acesso em: 8 jul. 2019

SILVA, L. do N.; NADAL, B. G. A participação do funcionário, enquanto educador, em processos de gestão escolar democrática e participativo. In: Os Desafios da Escola Pública Paranaense na perspectiva do professor PDE 2016. Governo do Paraná. Secretaria do Paraná. Versão online. V. I. ISBN 97885-8015-093-3. Disponível em: <cadernospde/pdebusca/producowww.diaadiaeducacao.pr.gov.br/portalses_pd e/2016/2016_artigo_gestao_uepg_lourivaldonascimentoesilva.pdf $>$. Acesso em: 17 jul. 2019.

VALLE, Arthur Schlunder. Trabalhadores técnico-administrativos em educação da UFMG: inserção institucional e superação da subalternidade. 2014. Dissertação apresentada no Programa de Pós-Graduação em Educação: Conhecimento e Inclusão Social da Faculdade de Educação da Universidade Federal de Minas Gerais. Belo Horizonte. Disponível em: <http://www.bibliotecadigital.ufmg.br/dspace/bitstream/handle/1843/BUBD9UHGC5/arthur_dissertacao_final2014.pdf?sequence=1 >. Acesso em: 02 abr. 2019. 